\title{
Impact of COVID-19 Pandemic on a Tertiary Care Center's Surgical Volume and Outcomes: a Single Institutional Study from Northeast India
}

\author{
Gaurav Das ${ }^{1} \cdot$ Sachin Khanna ${ }^{1}$ (D) Joydeep Purkayastha ${ }^{1} \cdot$ Abhijit Talukdar $^{1} \cdot$ Deepjyoti Kalita $^{1} \cdot$ Kiran Kamalasanan $^{1}$. \\ Srinivas Bannoth ${ }^{1}$. Jitin Yadav ${ }^{1}$. Shubhra Ramchandani ${ }^{2}$
}

Received: 1 September 2020 / Accepted: 27 July 2021 / Published online: 15 August 2021

(c) Indian Association of Surgical Oncology 2021

\begin{abstract}
In this study, we aimed to compare the surgical volume and outcomes between this COVID-19 period and data from nonCOVID-19 period of last year. A retrospective observational study was done in one single surgical unit of a dedicated oncology center in a peripheral location in India. The comparison was done between patients undergoing major cancer surgery during the COVID-19 pandemic period of 1st April to 30th June 2020, when a nation-wide lockdown was in force, to a comparable period of last year. Statistical analysis was done using SPSS software 20.0. A total of 72 patients underwent major cancer surgery during this period, with surgery for breast cancer $(n=26)$ being the major sub-site operated. This was a significant decrease from the total 209 major cancer surgeries performed during a similar period of last year (2019) $(p<0.05)$. There were several reasons for the decrease in surgical numbers, including the difficulty in travel and accommodation during the lockdown period. The mean distance of patient's residence from the treating hospital was $45.7 \mathrm{~km}$ (range 4 to $165 \mathrm{~km}$ ). Public transport was in a limbo and inter-state travel was restrictive with mandatory quarantine rules in effect. Morbidity associated with major surgeries was observed to be significantly less during the COVID-19 period compared to the pre-COVID-19 times ( $8.3 \%$ vs $17.2 \%$ with a $p$ value of $<0.05)$, which can probably be attributed to the lesser number of complex surgical procedures being performed. There was no significant difference between the total mortality percentages (2.8\% vs 3.8\%). A total of 156 PPE kits were used (3-4/per patient) throughout the in-hospital care of the surgical patients included in this study. In the midst of a pandemic, the delivery of surgical cancer care is an essential service and although the surgical volume is significantly hampered due to various reasons, the outcomes are largely unaffected.
\end{abstract}

Keywords COVID-19 $\cdot$ SARS-Cov-2 $\cdot$ Pandemic $\cdot$ Surgical oncology

\section{Introduction}

COVID-19 pandemic has led to an unprecedented adverse impact on health care services globally. This pandemic started in the Wuhan city of China where the first case was reported on 31st December 2019 [1, 2]. On 11th March 2020, the World Health Organization (WHO) had declared it as a pandemic and as a public health emergency

Sachin Khanna

drsachinkhanna1989@gmail.com

1 Department of Surgical Oncology, Dr. B. Borooah Cancer Institute, Guwahati, Assam, India

2 Department of Oncopathology, Dr. B. Borooah Cancer Institute, Guwahati, Assam, India of international concern [3]. A nationwide lockdown was imposed by the Government of India from 24th March 2020 to contain the spread of coronavirus infection. The pandemic has caused major disruption of health care services pervading all regions of the world with a calamitous impact on those with limited resources. Colossal challenges abound and include large-scale screening for COVID status, protection of health care providers (HCP), and judicious use of limited personal protective equipment (PPE) and other hospital resources [4]. To overcome these challenges, a number of scientific societies and organizations like American college of surgeons (ACS), Society of Surgical Oncology (SSO), European Society of Surgical Oncology (ESSO), and National Comprehensive Cancer Network (NCCN) among many have recommended triaging of surgical patients and proposed guidelines for handling patients waiting for cancer 
surgeries [5-10]. In this study, we have done a comparative analysis of surgical volume and outcomes between this COVID-19 period and data from non-COVID-19 period of last year.

\section{Materials and Methods}

This is a retrospective observational study. Patients who underwent surgical procedures under general anesthesia in the Department of Surgical Oncology at Dr. B. Booroah Cancer Institute within the time period 1st April 2020 to 30th June 2020 (3 months) were included in this study. Numbers of different surgical procedures performed and post-operative outcomes were noted. These results were compared with data from the previous year. Other parameters like distance of patients' home from our institute, number of patients with pre-operative COVID testing done, number of COVID patients detected at our institute and geographic location, and number of personnel protective kits (PPE) used were also noted. Statistical analysis was done using IBM SPSS Statistics for Windows, Version 20.0. Armonk, NY: IBM Corp. IBM Corp Released 2012.

\section{Protocol for PPE Kit Usage}

Personnel protection kits (PPE) comprised of disposable shoe covers, gown, goggles, cap, N95 mask, face shield, and gloves. These kits were worn by the health care team during the performance of the surgeries for a diagnosis of cancer. This was a universal practice until the time when preoperative real time polymerase chain reaction (RTPCR) testing for SARS CoV2 virus was available for all preoperative patients. Even after the adoption of routine preoperative RTPCR testing for SARS Cov2, the practice of usage of PPE kits during surgeries continued for a period of time (45 days) before it was stopped completely, upon the test result being negative.

\section{Results}

A total of 78 patients underwent surgeries under general anesthesia during this period of time. Six of them were minor procedures (axillary lymph node biopsy $=2$ and bone biopsy $=3$ and abdominal mass open biopsy $=1$ ) and were excluded. Seventy-two patients underwent major procedures. Most common procedure done was mastectomy $(n=17 ; 23.6 \%)$. Table 1 shows monthly distribution of different procedures done. Tables 2 and 3 are showing a comparison between preCovid-19 period and Covid-19 period in terms of surgical volume and peri-operative outcomes respectively.

Most of the patients belonged to the state of Assam ( $n=67$; $93 \%$ ) and the rest of them belonged to the neighboring state of Meghalaya $(n=5 ; 7 \%)$. Mean distance of patient's residence
Table 1 Monthly distribution of different procedures done

\begin{tabular}{lllll}
\hline Procedure done & April & May & June & Total \\
\hline Breast cases & & & & \\
$\quad$ Mastectomy & 5 & 2 & 10 & $17(23.6 \%)$ \\
BCS & 0 & 1 & 4 & $5(6.9 \%)$ \\
SLNB & 0 & 1 & 2 & $3(4.1 \%)$ \\
ALND & 0 & 0 & 1 & $1(1.4 \%)$ \\
GI cases & & & & \\
Exploratory laparotomy & 0 & 1 & 1 & $2(2.8 \%)$ \\
Colostomy/ileostomy & 3 & 2 & 4 & $9(12.5 \%)$ \\
DRG & 0 & 0 & 2 & $2(2.8 \%)$ \\
RC & 0 & 0 & 3 & $3(4.1 \%)$ \\
Sigmoid colectomy & 0 & 1 & 0 & $1(1.4 \%)$ \\
Hemicolectomy & 0 & 0 & 3 & $3(4.1 \%)$ \\
APR & 0 & 1 & 1 & $2(2.8 \%)$ \\
FJ & 4 & 4 & 1 & $9(12.5 \%)$ \\
GJ & 1 & 0 & 1 & $2(2.8 \%)$ \\
TTE & 0 & 0 & 1 & $1(1.4 \%)$ \\
VATS & 0 & 0 & $1 *$ & $1 *$ \\
Urology cases & & & & \\
HIO & 1 & 1 & 1 & $3(4.1 \%)$ \\
Bilateral orchiectomy & 0 & 0 & 1 & $1(1.4 \%)$ \\
Skin cancer & & & & \\
WLE & 1 & 0 & 2 & $3(4.1 \%)$ \\
STSG used & 0 & 0 & $1 *$ & $1 *$ \\
Local flap & 0 & 0 & $1 *$ & $1 *$ \\
Bone tumors & & & & \\
Resection and endoprosthesis & 0 & 0 & 1 & $1(1.4 \%)$ \\
Amputation (including one & 0 & 0 & 4 & $4(5.6 \%)$ \\
\hline
\end{tabular}

$B C S$ breast conservation surgery, SLNB sentinel lymph node biopsy, $A L N D$ axillary lymph node dissection, $D R G$ distal radical gastrectomy, $R C$ radical cholecystectomy, $A P R$ abdominoperineal resection, $F J$ feeding jejunostomy, $G J$ gastrojejunostomy, VATS video-assisted thoracoscopic surgery, TTE transthoracic esophagectomy, HIO high inguinal orchiectomy, $W L E$ wide local excision, STSG split thickness skin grafting, ILND inguinal lymph node dissection. *Not included in total count.

to our hospital was $45.7 \mathrm{~km}$ (range 4 to $165 \mathrm{~km}$ ). A total of 59 patients had COVID-19 testing (real-time polymerase chain reaction test) done before surgery and all were negative. In 43 patients, PPE kits were used by health personnel during surgery. A total of 156 PPE kits were used (3-4/per patient) throughout the in-hospital care (that is during surgeries only) of the patients included in this study. During this period, none of the surgical patients turned COVID-19 positive, although nine patients in our institute were detected as confirmed cases of COVID-19. Until the time this article was written, none of the personnel from operation theater staff, nursing team, anesthesia team, or surgery team was detected to have been infected with SARS Cov-2. 
Table 2 Comparison between surgeries done in this COVID-19 period and average number of surgeries done in 3 months period of previous year

\begin{tabular}{|c|c|c|c|}
\hline Procedure done & $\begin{array}{l}\text { Pre- } \\
\text { COVID-19 } \\
\text { period }\end{array}$ & $\begin{array}{l}\text { COVID- } \\
19 \text { period }\end{array}$ & $p$ value \\
\hline \multicolumn{4}{|l|}{ Breast cases } \\
\hline Mastectomy & 49 & 17 & $<0.0 .05$ \\
\hline $\mathrm{BCS}$ & 19 & 5 & $<0.05$ \\
\hline SLNB & 3 & 3 & 1.000 \\
\hline ALND & 2 & 1 & 0.564 \\
\hline Local flaps & $5 *$ & 0 & $<0.05$ \\
\hline \multicolumn{4}{|l|}{ GI cases } \\
\hline Exploratory laparotomy & 8 & 2 & 0.058 \\
\hline D Lap & 4 & 0 & $<0.05$ \\
\hline TTE & 8 & 1 & $<0.05$ \\
\hline Open & $3 *$ & $1 *$ & 0.317 \\
\hline VATS & $5^{*}$ & 0 & $<0.05$ \\
\hline THE & 3 & 0 & $<0.05$ \\
\hline Total gastrectomy & 3 & 0 & $<0.05$ \\
\hline Proximal gastrectomy & 1 & 0 & $<0.05$ \\
\hline DRG & 7 & 2 & 0.096 \\
\hline Palliative gastrectomy & 1 & 0 & $<0.05$ \\
\hline $\mathrm{RC}$ & 8 & 3 & 0.132 \\
\hline Whipple's procedure & 3 & 0 & $<0.05$ \\
\hline Distal pancreatectomy & 1 & 0 & $<0.05$ \\
\hline Hepatectomy & 1 & 0 & $<0.05$ \\
\hline Hemicolectomy & 8 & 3 & 0.132 \\
\hline Sigmoid colectomy & 2 & 1 & 0.564 \\
\hline AR/LAR/ULAR & 6 & 0 & $<0.05$ \\
\hline APR & 5 & 2 & 0.257 \\
\hline Colostomy/ileostomy & 6 & 9 & 0.439 \\
\hline Colostomy/ileostomy closure & 3 & 0 & $<0.05$ \\
\hline FJ & 10 & 9 & 0.819 \\
\hline GJ & 4 & 2 & 0.457 \\
\hline FG & 3 & 0 & $<0.05$ \\
\hline \multicolumn{4}{|l|}{ Urology cases } \\
\hline Radical nephrectomy & 2 & 0 & $<0.05$ \\
\hline Penectomy & 3 & 0 & $<0.05$ \\
\hline Adrenalectomy & 1 & 0 & $<0.05$ \\
\hline HIO & 2 & 3 & 0.655 \\
\hline Bilateral orchiectomy & 4 & 1 & 0.180 \\
\hline \multicolumn{4}{|l|}{ Skin cancer } \\
\hline WLE & 9 & 3 & 0.083 \\
\hline STSG used & $4 *$ & $1 *$ & 0.18 \\
\hline Local flap & $3 *$ & $1 *$ & 0.317 \\
\hline ILND & $3 *$ & 0 & $<0.05$ \\
\hline \multicolumn{4}{|l|}{ Soft tissue sarcoma } \\
\hline RPLND & 2 & 0 & $<0.05$ \\
\hline WLE & 8 & 0 & $<0.05$ \\
\hline STSG & $3 *$ & 0 & $<0.05$ \\
\hline Local flaps & $2 *$ & 0 & $<0.05$ \\
\hline
\end{tabular}

Table 2 (continued)

\begin{tabular}{llll}
\hline Procedure done & $\begin{array}{l}\text { Pre- } \\
\text { COVID-19 } \\
\text { period }\end{array}$ & $\begin{array}{l}\text { COVID- } \\
19 \text { period }\end{array}$ & $p$ value \\
\hline Bone tumors & & 1 & 0.18 \\
$\quad$ Resection and endoprosthesis & 4 & 0 & $<0.05$ \\
Internal hemipelvectomy & 1 & 4 & 0.739 \\
Amputation & 5 & 72 & $<0.05$ \\
Total & 209 & & \\
\hline
\end{tabular}

$B C S$ breast conservation surgery, SLNB sentinel lymph node biopsy, $A L N D$ axillary lymph node dissection, $D$ Lap diagnostic laparoscopy, $D R G$ distal radical gastrectomy, $R C$ radical cholecystectomy, $A P R$ abdominoperineal resection, VATS video-assisted thoracoscopic surgery, TTE transthoracic esophagectomy, THE transhiatal esophagectomy, $A R$ anterior resection, $L A R$ low anterior resection, ULAR ultralow anterior resection, $F J$ feeding jejunostomy, $G J$ gastrojejunostomy, $F G$ feeding gastrostomy, HIO high inguinal orchiectomy, $R P L N D$ retroperitoneal lymph node dissection, $W L E$ wide local excision, STSG split thickness skin grafting, ILND inguinal lymph node dissection. *Not included in total count.

Table 3 Comparison between peri-operative outcomes of patients undergoing surgeries in pre-COVID era and this COVID era

\begin{tabular}{llll}
\hline Complications & $\begin{array}{l}\text { Pre-COVID-19 } \\
\text { period }\end{array}$ & COVID-19 period & $p$ value \\
\hline SSI & $13(6.2 \%)$ & $3(4.1 \%)$ & \\
Bleeding & $3(1.4 \%)$ & 0 & $<0.05$ \\
Flap necrosis & $4(1.9 \%)$ & 0 & $<0.05$ \\
Chest infections & $8(3.8 \%)$ & $2(2.8 \%)$ & 0.874 \\
Bile leak & $2(0.9 \%)$ & 0 & $<0.05$ \\
Paralytic ileus & $3(1.4 \%)$ & 0 & $<0.05$ \\
Re-operation & $3(1.4 \%)$ & $1(1.3 \%)$ & 0.918 \\
Total morbidity & $36(17.2 \%)$ & $6(8.3 \%)$ & $<0.05$ \\
Mortality & $8(3.8 \%)$ & $2(2.8 \%)$ & 0.764 \\
\hline
\end{tabular}

\section{Discussion}

At the very beginning of the COVID-19 pandemic, there was widespread fear and apprehension regarding the unknown implications of having SARS-Cov-2 infection among surgical patients and surgical care providers, in terms of uncertain morbidity and mortality associated with novel virus. As news started pouring in thick and fast regarding high numbers of case fatalities from across the globe, especially in Italy and Spain, the scenario was one of being overly circumspect. Guidelines came in to recommend that surgical care that was not essential or time-critical could be delayed or deferred to a later date when the pandemic subsides. The timeline of the pandemic itself has remained unfathomable. However, even in the midst of a pandemic, certain surgical procedures must be performed and cancer surgery is one 
such domain, considering the curative potential in several cancers. A complete neglect of certain surgical services would be considered unwanted collateral damage, and inadvertently increase the number of deaths and life-years lost owing to the COVID-19 pandemic [11].

The first confirmed case of COVID-19 in Assam was reported in 31st of March 2020, which was about 2 months later than the outbreak noted in other parts of the country. The country-wide lockdown started in April and this explains why PPE kits were not used in every case prior to lockdown. The institution of regular preoperative COVID-19 testing took still more time, due to logistics of availability of testing. In-house testing started at a later date, after capacity building and establishment of the testing center.

We have included the surgical algorithm that was actually followed (execution phase) (Fig. 1).

Since the imposition of lockdown in India (24th March 2020), the number of surgical procedures performed at our institute has decreased significantly. In our study, we saw that the number of cases done quarterly was reduced to

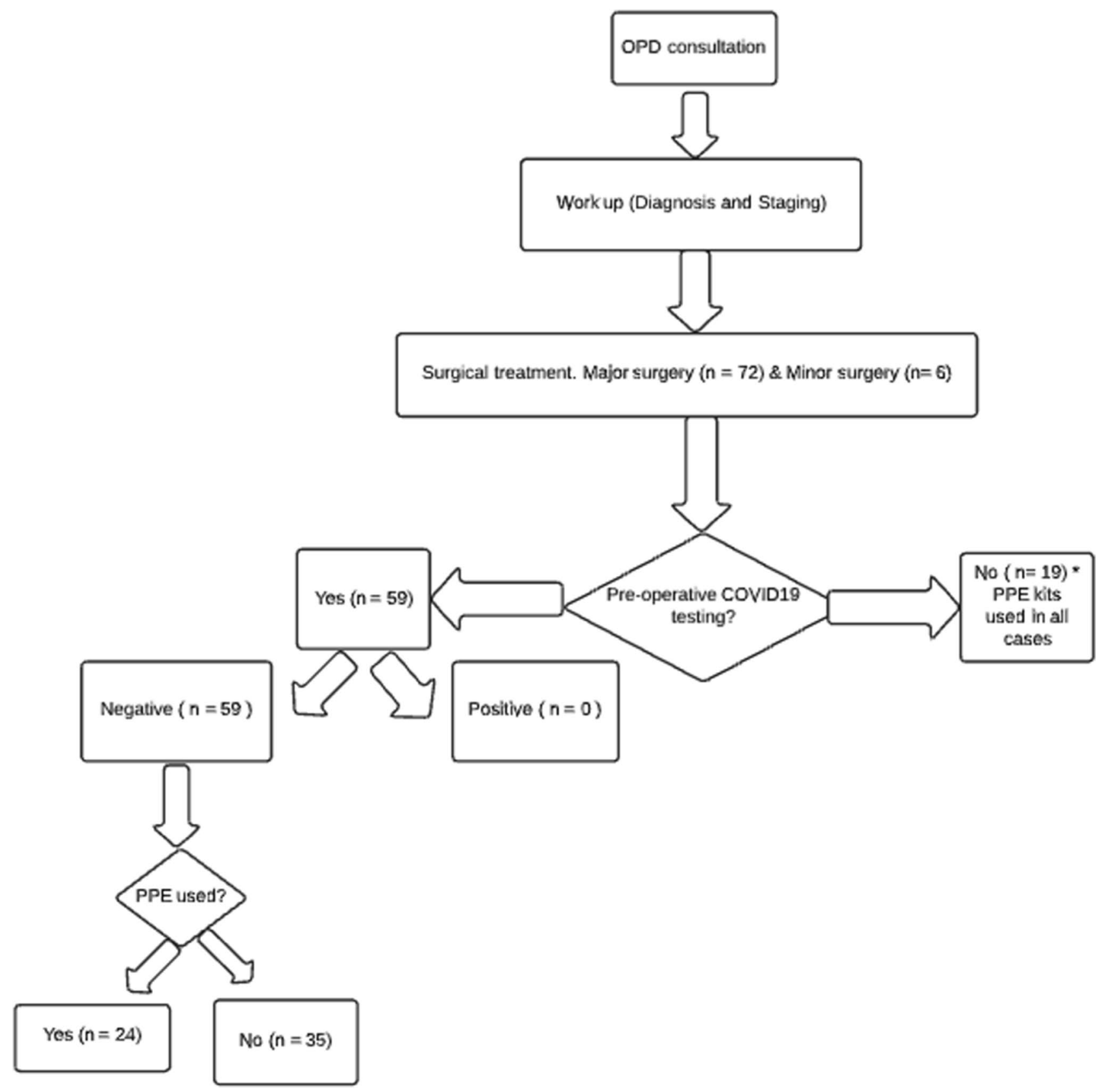

Fig. 1 Surgical algorithm followed 
almost one-third (209 vs 72). The decrease in case volume was more during first 2 months than the third month. This was probably due to combined effect of lockdown and lack of proper guidelines for surgery in cancer patients. Similar results were given by a study conducted by Chang et al. [12]. In this US-based study, it was found that after the declaration of a national state of emergency, the decline in cases per week was significantly lower than baseline and the previous year $(428.3 \pm 51.5$ vs $166.6 \pm 59.8$ cases/ week; $p<0.001)$.

It was also seen that although the total number of elective cancer surgeries was significantly decreased, the number of emergency surgeries remained more or less similar to the preCOVID time. Frequencies of procedures like feeding jejunostomy (10 vs 9), feeding gastrostomy (4 vs 2), and emergency colostomy/ileostomy (6 vs 9) were similar in both time periods. In fact number of emergency colostomy/ileostomy done during this COVID period was more than pre-COVID period, although not statistically significant $(p=0.439$ ).

Out of 72 patients operated, 59 patients had pre-op COVID-19 testing done. Most of the patients who were operated in this period belonged to Assam (93\%) and rest from Meghalaya (7\%). The mean distance of patients' residence was $45.72 \mathrm{~km}(4-165 \mathrm{~km})$. This was due to strict lockdown, lack of public transport, and restriction of travel across state borders, including mandatory quarantine rules.

Interestingly, total morbidity was actually decreased in COVID-19 time period group. However, this can be attributed to proportionately less number of complex surgeries performed during this period.

In our study we have explored the feasibility of giving surgical services to cancer patients amidst this COVID period. In our opinion, the number of surgical procedures came down mostly due to lockdown itself. We normally receive patients from the entire Northeast region, but due to lack of transportation services, the number of patients that could avail our services was drastically decreased. However, we as a team tried our best to provide our services to those who could avail them. We started using PPE kits at the earliest, started pre-op COVID-19 testing and followed Government-issued set protocols. By doing so, we found that providing surgical services was feasible with essentially no compromise in safety of the patient and the health care provider.

\section{Conclusion}

In the midst of a pandemic, the delivery of surgical cancer care is an essential service and although the surgical volume is significantly hampered due to various reasons, the outcomes are largely unaffected.

\section{Declarations}

Ethics approval Institutional ethical clearance was taken for this study.

Conflict of interest The authors declare no competing interests.

\section{References}

1. Zhu N, Zhang D, Wang W, Li X, Yang B, Song J et al (2019) (2020) A novel coronavirus from patients with pneumonia in China. N Engl J Med 382(8):727-733

2. Wang D, Hu B, Hu C, Zhu F, Liu X, Zhang J et al (2020) Clinical characteristics of 138 hospitalized patients with 2019 novel coronavirus-infected pneumonia in Wuhan. China JAMA 323(11):1061-1069. https://doi.org/10.1001/jama.2020.1585

3. Novel Coronavirus (2019-nCoV) situation reports [Internet]. [cited 2020 Apr 8]. Available from: https://www.who.int/emerg encies/diseases/novel-coronavirus-2019/situation-reports

4. Deo SV, Kumar S, Kumar N, Saikia J, Bhoriwal S, Bhatnagar S, Sharma A (2020) Guiding principles for cancer surgery during the COVID-19 pandemic. Indian J Surg Oncol 6:1

5. COVID-19 Guidelines for triage of cancer surgery patients [Internet]. American College of Surgeons. [cited 2020 July 10]. Available from: https://www.facs.org/covid-19/clinical-guidance/elect ive-case/cancer-surgery

6. COVID-19 Resources [Internet]. Society of Surgical Oncology. [cited 2020 July 10]. Available from: https://www.surgonc.org/ resources/covid-19-resources/

7. NCCN covid-19 resources [Internet]. [cited 2020 July 10]. Available from: https://www.nccn.org/covid19/

8. theihns. The Irish Head and Neck Society [Internet]. theihns. [cited 2020 Apr 9]. Available from: https://theihns.com/covid19

9. BASO - The British Association of Surgical Oncology :: ESSO [Internet]. [cited 2020 July 10]. Available from: https://www. essoweb.org/baso/

10. Guidelines and Recent Publications [Internet]. British Gynaecological Cancer Society. [cited 2020 July 10]. Available from: https://www.bgcs.org.uk/professionals/guidelines-forrecent-publi cations/

11. Søreide K, Hallet J, Matthews JB, Schnitzbauer AA, Line PD, Lai PB, Otero J, Callegaro D, Warner SG, Baxter NN, Teh CS (2020) Immediate and long-term impact of the COVID-19 pandemic on delivery of surgical services. Br J Surg 107(10):1250-1261

12. Chang EI, Liu JJ (2020) Flattening the curve in oncologic surgery: Impact of Covid-19 on surgery at tertiary care cancer center. J Surg Oncol 122(4):602-607

Publisher's Note Springer Nature remains neutral with regard to jurisdictional claims in published maps and institutional affiliations. 